\title{
Microstructural and Fracture Analysis of Aged Cast Duplex Steel
}

\author{
D. Dyja, ${ }^{1, a}$ Z. Stradomski, ${ }^{1, b}$ and A. Pirek ${ }^{1, c}$ \\ ${ }^{1}$ Czestochowa University of Technology, Institute of Materials Engineering, Czestochowa, Poland \\ adyjad@mim.pcz.czest.pl, b zbigniew@mim.pcz.czest.pl, c pireka@mim.pcz.czest.pl
}

The effect of increased carbon content and heat treatment parameters on the microstructure and selected properties of ferritic-austenitic duplex cast steel is discussed. Test results show that the cast steel microstructure after the solution heat treatment changes substantially with increasing carbon content. Ageing after the solution heat treatment results in approx. $20 \%$ increase in hardness and a few-times decrease in impact strength. Fractographic examinations show that fracture surfaces of specimens of steel with low carbon content are typically of transcrystalline ductile micromechanism. An increase in carbon content is accompanied by a decline in ductility areas, while fracture of specimens is of mixed nature: ductile and brittle. After ageing, only cases of mixed fracture were observed.

Keywords: duplex cast steel, heat treatment, brittle fracture, carbides, impact energy.

Introduction. Chemical composition of cast alloyed duplex steels is selected, in order to ensure the required properties via appropriate amount of ferrite and austenite in the microstructure. However, depending on the chemical composition, conditions of thermal treatment and manufacturing technology intermetallic phases $(\sigma, \chi, \pi, R)$ and carbides can cause increase of brittleness and reduction of corrosion resistance $[1,2]$. As observed in literature and shown in numerous advertising materials of casting companies this is promoted by the trend to increase the carbon content above the value most often presented in standards $\left(C_{\max }=0.03 \%\right)$. Higher carbon content facilitates the handling of metallurgical process (in particular, in casting shops which do not have secondary metallurgy) and has a favourable effect on erosion resistance of duplex cast steels [3, 4]. However, an increased carbon content creates qualitative problems related both to the solidification course and processes during cooling of the casing in the solid state, what has been described in detail in $[5,6]$.

Despite technological difficulties related to casting propensity for cracking, the optimum combination of mechanical properties with erosion wear resistance makes that the demand for this material permanently increases, especially for the components operating in environment of liquid solutions heavily polluted with solid particles [7] Erosion-corrosion influence of such environment is the reason of costly breakdowns and down times caused by premature wear of components. This applies, in particular, to components of dewatering sets including mainly pump impellers, sleeves or elements of pipelines [8]. This problem is resolved, among others, by the use of high-alloy $\mathrm{Fe}-\mathrm{Cr}-\mathrm{Ni}$ cast steels containing addition of $3-4 \%$ of copper, which increases resistance to acid action and ensures obtaining of precipitation hardening by $\varepsilon$-Cu phase as a result of ageing at $480^{\circ} \mathrm{C}$ [9]. The aim of this study was determination of the effect of increased carbon content on selected mechanical and plastic properties of the solution heat-treated and aged duplex cast steel.

Materials and Methodology. The chemical composition (in mass \%) of the ferritic-austenitic duplex cast steels used for the present work is listed in Table 1. The cast steel was solution heat-treated in water after two-hour soaking at $1080^{\circ} \mathrm{C}$ and then aged at $480^{\circ} \mathrm{C}$ for 4 hours. Specimens for optical metallography (OM) were chemically etched in a $30 \mathrm{~g}$ potassium ferricyanide $+30 \mathrm{~g}$ potassium hydroxide $+60 \mathrm{ml}$ distilled water. Hardness was measured by the Brinell method under a load of $1838 \mathrm{~N}$ with a steel ball of 
a diameter of $2.5 \mathrm{~mm}$. Charpy impact energy was measured on Charpy V specimens at ambient temperature on a hammer of an initial energy of $300 \mathrm{~J}$. Fractography of the broken specimens was performed in a JEOL JSM 5400 scanning electron microscope.

$\mathrm{T}$ a b 1 e 1

Chemical Composition of Examined Cast Steels

\begin{tabular}{|c|c|c|c|c|c|c|c|c|c|c|}
\hline Heat No. & $\mathrm{C}$ & $\mathrm{Cr}$ & $\mathrm{Ni}$ & $\mathrm{Cu}$ & $\mathrm{Mo}$ & $\mathrm{Mn}$ & $\mathrm{N}$ & $\mathrm{Si}$ & $\mathrm{S}$ & $\mathrm{P}$ \\
\hline 1 & 0.028 & 24.20 & 8.82 & 0.02 & 2.30 & 0.46 & 0.068 & 0.85 & 0.010 & 0.011 \\
\hline 2 & 0.040 & 24.70 & 6.74 & 3.11 & 2.22 & 0.88 & 0.140 & 0.88 & 0.012 & 0.017 \\
\hline 3 & 0.055 & 24.40 & 6.71 & 3.08 & 2.40 & 0.14 & 0.085 & 0.81 & 0.020 & 0.020 \\
\hline 4 & 0.060 & 24.70 & 6.91 & 3.00 & 2.90 & 0.14 & 0.078 & 0.73 & 0.018 & 0.019 \\
\hline 5 & 0.090 & 24.00 & 8.02 & 2.60 & 2.25 & 0.24 & 0.080 & 1.05 & 0.010 & 0.016 \\
\hline 6 & 0.120 & 25.00 & 6.95 & 2.85 & 2.56 & 0.19 & 0.075 & 0.90 & 0.030 & 0.020 \\
\hline
\end{tabular}

Results. Examples of the steel microstructure after the solution heat treatment from $1080^{\circ} \mathrm{C} / 2 \mathrm{~h} /$ water are presented in Fig. 1 . Cast steels from heat $1-3$, containing $C_{\max }=$ $0.055 \%$ feature a two-phase ferritic-austenitic microstructure with austenite grains distributed in the ferritic matrix (Fig. 1a).
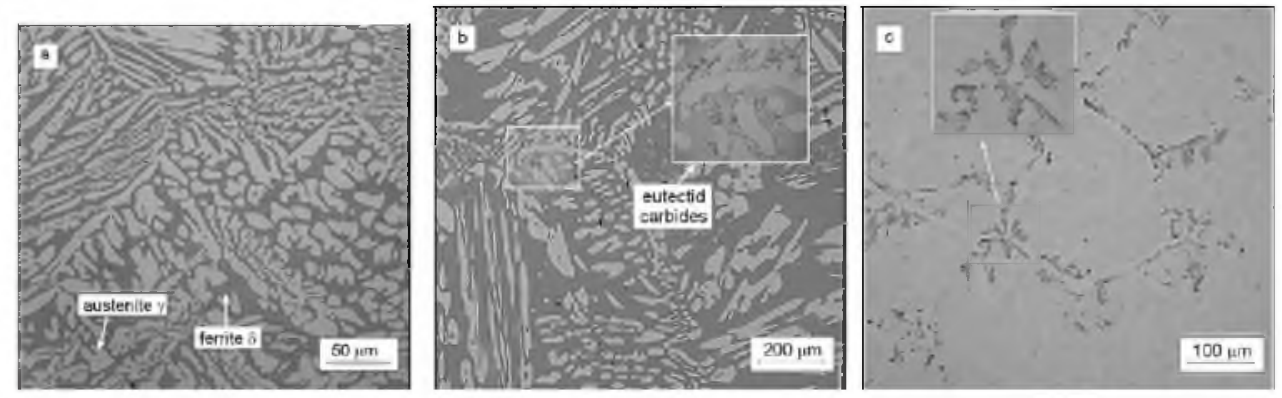

Fig. 1. Microstructure of the cast steel: (a) heat 1 ; (b) heat 4 ; (c) heat 6 , after $1080^{\circ} \mathrm{C} / 2 \mathrm{~h} /$ water.

A carbide eutectic (Fig. 1b and 1c), non-dissolved during the heat treatment, is observed in the microstructure of solution heat-treated cast steel with increased carbon content (heat 4-6); its volume fraction increases from $V_{E}=0.03 \%(0.06 \% \mathrm{C}$ for heat 4$)$ to $V_{E}=2.00 \%(0.12 \% \mathrm{C}$ for heat 6$)$ with carbon content increasing. Effects of ageing at $480^{\circ} \mathrm{C}$ in the microstructure changes are not visible via optical microscopy. However, as a result of isothermal holding at this temperature, a spinodal decomposition of ferrite occurs (with creation of $\alpha$ phase, enriched in iron, and chromium-rich $\alpha^{\prime}$ phase) as well as precipitation in the ferrite of copper-rich $\varepsilon$-Cu phase.

Results of measurements of the steel hardness and impact energy after ageing specified in Table 2 show a small, about $20 \%$, increase in hardness as compared to the solution heat-treated material with simultaneous clear decline in impact energy. General increase in the steel hardness after ageing is affected mainly by the increase in ferrite microhardness related to spinodal decomposition into $\alpha$ and $\alpha^{\prime}$ phase as well as to precipitation of copper-rich $\varepsilon$-Cu phase. Noteworthy is very unfavourable influence of increased carbon content on cast steel impact energy. As shown in Table 2, the impact energy of cast steel containing $0.028 \%$ carbon (heat 1) after solution heat treatment has to $160 \mathrm{~J}$ and falls to $10 \mathrm{~J}$ for cast steel containing $0.12 \%$ carbon (heat 6 ). The ageing at $480^{\circ} \mathrm{C}$, causing a slight increase in hardness, results in a clear few-times decrease in the impact energy as compared to solution heat-treated cast steel. 
Microstructural and Fracture Analysis of Aged Cast Duplex Steel

$\mathrm{T}$ a b l e 2

Results of Hardness, Microhardness, and Impact Energy of Investigated Steels

\begin{tabular}{|c|c|c|c|c|c|c|c|c|c|c|c|c|}
\hline \multirow[t]{2}{*}{ Process } & \multicolumn{4}{|c|}{ Heat 1} & \multicolumn{4}{|c|}{ Heat 2} & \multicolumn{4}{|c|}{ Heat 3} \\
\hline & $H B$ & $K V$ & $H V_{\delta}$ & $H V_{\gamma}$ & $H B$ & $K V$ & $H V_{\delta}$ & $H V_{\gamma}$ & $H B$ & $K V$ & $H V_{\delta}$ & $H V_{\gamma}$ \\
\hline Solutioning & 215 & 160 & 335 & 205 & 245 & 148 & 353 & 216 & 242 & 142 & 350 & 214 \\
\hline \multirow[t]{3}{*}{ Ageing } & 259 & 58 & 420 & 210 & 279 & 55 & 434 & 232 & 285 & 50 & 437 & 233 \\
\hline & \multicolumn{4}{|c|}{ Heat 4} & \multicolumn{4}{|c|}{ Heat 5} & \multicolumn{4}{|c|}{ Heat 6} \\
\hline & $H B$ & $K V$ & $H V_{\delta}$ & $H V_{\gamma}$ & $H B$ & $K V$ & $H V_{\delta}$ & $H V_{\gamma}$ & $H B$ & $K V$ & $H V_{\delta}$ & $H V_{\gamma}$ \\
\hline Solutioning & 251 & 118 & 348 & 230 & 258 & 38 & 351 & 228 & 266 & 10 & 355 & 240 \\
\hline Ageing & 298 & 28 & 439 & 260 & 307 & 19 & 445 & 239 & 313 & 6 & 450 & 248 \\
\hline
\end{tabular}

Note. Values of $H V_{\delta}$ and $H V_{\gamma}$ correspond ferrite and austenite microhardnesses, respectively.

To explain microstructural origins of changes in mechanical properties, selected fracture surfaces of broken impact test specimens were subjected to fractographic analysis using SEM. The examples of fracture surfaces observed are presented in Figs. 2 and 3.
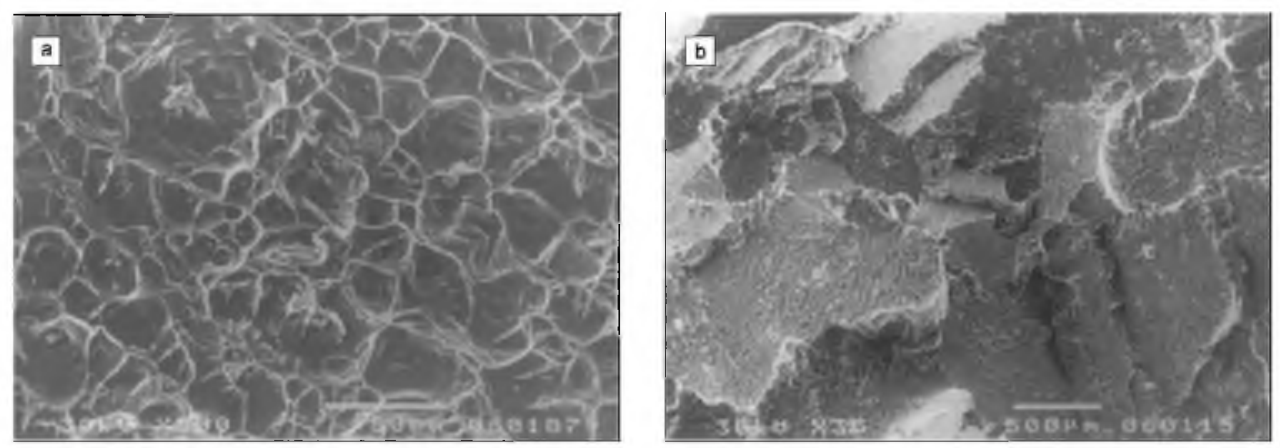

Fig. 2. SEM microphotographs of the steel: (a) heat 1 ; (b) heat 6 ; after $1080^{\circ} \mathrm{C} / 2 \mathrm{~h} /$ water.
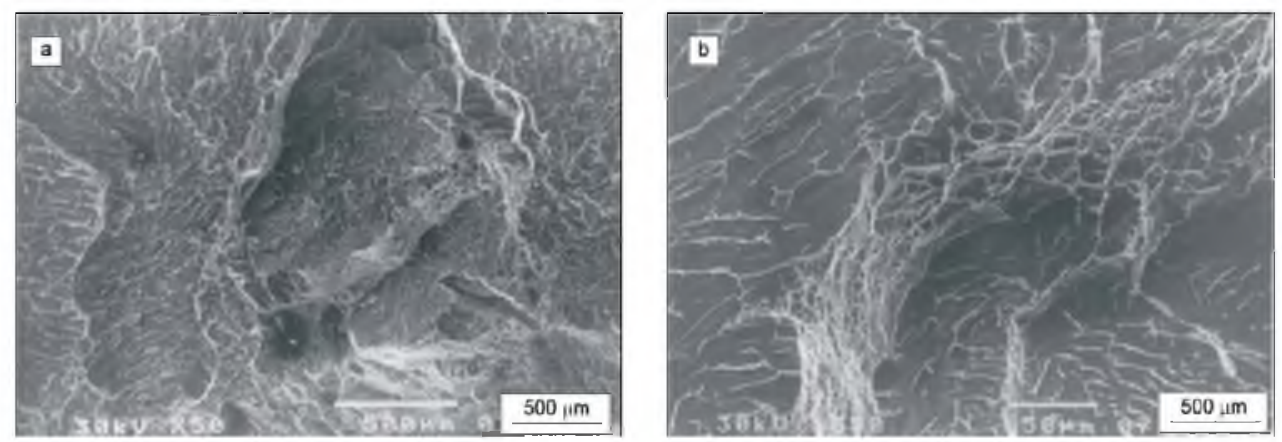

Fig. 3. SEM microphotograph of the investigated steel after the ageing (heat 1).

For the steels with low carbon content after the solution heat treatment characteristic ductile fracture is observed (Fig. 2a) and sulphide inclusions, most often of spheroidal shape, have been revealed on fracture surfaces. An increase in carbon content in the cast steel is accompanied by a decline in ductility areas, specimen fractures are of mixed ductile and brittle nature (Fig. 2b). Morphology of specimen fracture is subject of significant change after ageing. Two mechanisms of cracking are observed on the 
surfaces: transcrystalline cleavage and ductile, the former one prevailing. A typical example of mixed fracture is presented in Fig. 3. Numerous faults and changes of cracking surfaces and only a few traces of ductile cracking exist in elementary interfaces.

\section{Conclusions}

1. The cast steel structure after the solution heat treatment changes substantially with increasing carbon content. The steels containing $C_{\max }=0.055 \%$ feature a ferriticaustenitic structure. In the microstructure of solution heat-treated steel with increased carbon content a carbide eutectic, non-dissolved during the heat treatment, is observed. Isothermal holding at $480^{\circ} \mathrm{C}$ results in spinodal decomposition of ferrite with creation of $\alpha$ and $\alpha^{\prime}$ phases as well as precipitation in the ferrite of $\varepsilon$ - $\mathrm{Cu}$ phases.

2. Duplex cast steel allows obtaining very high impact energy after the solution heat treatment, reaching $160 \mathrm{~J}$, however small fraction of eutectic carbides in the cast steel containing $0.06 \% \mathrm{C}$ reduces the impact strength to about $118 \mathrm{~J}$. Once the carbide eutectic creates a network (in the steel containing $0.12 \% \mathrm{C}$ ) the impact strength does not exceed $10 \mathrm{~J}$.

3. Ageing after the solution heat treatment results in approx. $20 \%$ increase in hardness related to precipitation processes in the ferrite, simultaneous with a few-times decrease in impact energy.

4. Fractographic examinations have shown that fractures of specimens of cast steel with low carbon content are typical ductile transcrystalline micromechanism. The size of ductile fracture 'dimples' depends clearly on the size of their initiators, which are pretty large inclusions of third-type sulphides and much smaller precipitates of carbides or carbonitrides. An increase in carbon content in the cast steel is accompanied by a decline in ductility areas and fracture surfaces of specimens are of mixed nature, ductile and brittle.

1. R. A. Perren, T. A. Suter, C. Solenthaler, et al., "Corrosion resistance of super duplex stainless steels in chloride ion containing environments: investigations by means of a new microelectrochemical method. II. Influence of precipitates," Corros. Sci., 43, 727-745 (2001).

2. C. J. Park, V. R. Shankar, and H. S. Kwon, "Effect of sigma phase on the initiation and propagation of pitting corrosion of duplex stainless steel," Corrosion, 61, No. 1, 76-83 (2005).

3. J. Tissier, D. Balloy, J. Dairon, et al., "Décarborution sous vide: une solution á la portée des PME de fonderie," Fonderie: Fondeur d'Aujourd'hui, No. 246, 28-39 (2005).

4. W. Hubner and E. Leitel, "Peculiarities of erosion-corrosion processes," Tribology Int., 29. No. 3, 199-206 (1996).

5. Z. Stradomski, S. Stachura, and D. Dyja, "Technological problems in elaboration of massive casting from duplex cast steel," in: Stainless Steel World Conference\&Expo, Maastricht. Netherlands (2005), pp. 363-368.

6. Z. Stradomski and D. Dyja, "Influence of carbon content on the segregation processes in duplex cast steel," Arch. Foundry Eng., 7, Issue 1, 139-142 (2007).

7. J. Peultier, F. Barrau, and J. P. Audouard, "Corrosion resistance of duplex and superduplex stainless steels for air pollution control process systems," Stainless Steel World, 17, 45-55 (2005).

8. K. A. Bakken, "Cost effective materials selections - what is true?," in: Stainless Steel World Conference\&Expo, Maastricht, Netherlands (2005), pp. 18-23.

9. D. Dyja and Z. Stradomski, "Quench ageing behavior of duplex cast steel with nano-scale $\varepsilon$-Cu particles," J. Achiev. Mater. Manufact. Eng., 20, Issue 1-2, 435-438 (2007). 